\title{
The S20G substitution in hIAPP is more amyloidogenic and cytotoxic than wild-type hIAPP in mouse islets
}

\author{
Daniel T. Meier ${ }^{1,2} \cdot$ Leon Entrup ${ }^{1,2} \cdot$ Andrew T. Templin ${ }^{1,2} \cdot$ Meghan F. Hogan ${ }^{1,2}$. \\ Mahnaz Mellati $^{1,2}$ - Sakeneh Zraika ${ }^{1,2}$ - Rebecca L. Hull ${ }^{1,2}$ - Steven E. Kahn ${ }^{1,2}$
}

Received: 21 August 2015 / Accepted: 15 June 2016/Published online: 1 September 2016

(C) Springer-Verlag (outside the USA) 2016

\begin{abstract}
Aims/hypothesis The S20G human islet amyloid polypeptide (hIAPP) substitution is associated with an earlier onset of type 2 diabetes in humans. Studies of synthetic S20G hIAPP in cell-free systems and immortalised beta cells have suggested that this may be due to increased hIAPP amyloidogenicity and cytotoxicity. Thus, using primary islets from mice with endogenous S20G hIAPP expression, we sought to determine whether the S20G gene mutation leads to increased amyloidinduced toxicity, beta cell loss and reduced beta cell function. Methods Islets from mice in which mouse Iapp was replaced with human wild-type or S20G hIAPP were isolated and cultured in vitro under amyloid-forming conditions. Levels of insulin and hIAPP mRNA and protein, amyloid deposition and beta cell apoptosis and area, as well as glucosestimulated insulin and hIAPP secretion, were quantified. Results Islets expressing S20G hIAPP cultured in $16.7 \mathrm{mmol} /$ 1 glucose demonstrated increased amyloid deposition and beta cell apoptosis, reduced beta cell area, decreased insulin content and diminished glucose-stimulated insulin secretion, compared with islets expressing wild-type hIAPP. Amyloid deposition and beta cell apoptosis were also increased when S20G islets were cultured in $11.1 \mathrm{mmol} / \mathrm{l}$ glucose (the concentration that is thought to be physiological for mouse islets). Conclusions/interpretation S20G hIAPP reduces beta cell number and function, thereby possibly explaining the earlier
\end{abstract}

Steven E. Kahn

skahn@uw.edu

1 VA Puget Sound Health Care System, 1660 S. Columbian Way, Seattle, WA 98108, USA

2 University of Washington, Seattle, WA, USA onset of type 2 diabetes in individuals carrying this gene mutation.

Keywords Amylin · Amyloid · Beta cell · Insulin secretion · Islet · Islet amyloid polypeptide · Toxicity $\cdot$ Type 2 diabetes
Abbreviations
GSIS Glucose-stimulated insulin secretion
hIAPP Human islet amyloid polypeptide
S20G Serine-to-glycine substitution at amino acid 20
VAPSHCS VA Puget Sound Health Care System

\section{Introduction}

Human islet amyloid polypeptide (hIAPP; amylin) is a 37-amino-acid peptide that is co-secreted with insulin by the pancreatic beta cell. In type 2 diabetes, aggregation of hIAPP and its deposition as amyloid in the islet is associated with beta cell apoptosis [1].

Various modifications in the amino acid sequence of hIAPP have been shown to alter its aggregation properties. However, to date only one hIAPP polymorphism has been identified in humans. This serine-to-glycine substitution at position 20 (S20G) described in Asian populations is associated with an earlier onset of type 2 diabetes when comparing individuals with and without this substitution [2,3]. Findings with cell lines using either synthetic hIAPP peptides applied exogenously or plasmid transfection approaches generally suggest that the S20G substitution renders hIAPP more toxic [4-6]. Based on observations in cell-free systems, it has also been proposed that S20G hIAPP aggregates faster than wild-type hIAPP [4-6]. This has been confirmed by structural studies reporting that S20G hIAPP fibril formation is enhanced due 
either to increased local flexibility or to conformational preorganisation in the monomer prior to self-assembly [7].

Given these findings we sought to determine whether endogenous hIAPP bearing the S20G substitution exhibits increased amyloidogenicity and cytotoxicity. For this purpose, we used transgenic islets from mice in which wild-type $\mathrm{h} I A P P$ or S20G hIAPP had been knocked into the endogenous mouse Iapp locus [8]. Here, we report our findings that islets bearing the S20G gene mutation exhibit increased amyloid-induced beta cell apoptosis, decreased beta cell area and impaired insulin release.

\section{Methods}

Islet experiments C57BL/6NHsd mice (Harlan, Indianapolis, IN, USA) with wild-type $\mathrm{h} I A P P$ or S20G hIAPP knocked into the endogenous mouse Iapp locus [8] were bred and maintained at the VA Puget Sound Health Care System (VAPSHCS). Islets from 10-week-old male or female mice were isolated by collagenase digestion, recovered overnight in RPMI 1640 medium and subsequently cultured in media containing either 11.1 or $16.7 \mathrm{mmol} / \mathrm{l}$ glucose for $144 \mathrm{~h}$, with media being renewed every $48 \mathrm{~h}$. The VAPSHCS Institutional Animal Care and Use Committee approved the studies.

Assessment of islet morphology Islets were fixed in formalin, embedded in paraffin, sectioned and labelled with thioflavin S $(0.5 \% \mathrm{w} / \mathrm{v}$; Sigma-Aldrich, St Louis, MO, USA) to visualise amyloid deposits, insulin antibody (1:2000; clone K36AC10; Sigma-Aldrich) to visualise beta cells and Hoechst 33258 ( $2 \mu \mathrm{g} / \mathrm{ml}$; Sigma-Aldrich) to visualise nuclei. Amyloid prevalence (no. of amyloid-positive islets/ no. of total islets $\times 100$ ) and amyloid severity (amyloid area/islet area $\times 100$ ) were quantified on 14-35 islets (average 26) per sample using a computer-based quantitative method. Beta cell apoptosis was determined by staining with propidium iodide (9 $\mu \mathrm{g} / \mathrm{ml}$; Invitrogen, Grand Island, NY, USA) and counterstaining with an insulin antibody as above on 18-42 (average 28) islets per sample [9, 10]. The observer was blinded to the genotype and culture condition of the islets. A detailed description of these processes has been published [11].

Beta cell secretory function After $144 \mathrm{~h}$ culture in either 11.1 or $16.7 \mathrm{mmol} / 1$ glucose, islets were incubated in $2.8 \mathrm{mmol} / 1$ Krebs buffer for $1.5 \mathrm{~h}$, followed by incubation of triplicate samples of five islets each in either 2.8 or $20 \mathrm{mmol} / 1$ glucose for $1 \mathrm{~h}$. Thereafter, supernatant fractions were collected and islet content extracted with acid-ethanol from islets exposed to $2.8 \mathrm{mmol} / \mathrm{l}$ glucose. Insulin (ALPCO, Salem, NH, USA) and hIAPP (EZHA-52K; Millipore, St. Charles, MO, USA) concentrations were measured using ELISAs. The IAPP
ELISA employs a monoclonal capture antibody (F002; binds all molecular forms of (pro)IAPP), and a monoclonal detection antibody (F025; binds amidated IAPP at its $\mathrm{C}$ terminus) [12]. hIAPP release at basal $(2.8 \mathrm{mmol} / \mathrm{l})$ glucose was below the detection limit of the assay under all conditions.

RNA quantification RNA was isolated, reverse transcribed and gene expression determined by Taqman real-time quantitative PCR using 18S as housekeeping gene (Applied Biosystems, Foster City, CA, USA).

Statistical analysis Data are presented as mean $\pm \mathrm{SEM}$. Statistical significance was determined using Student's $t$ test or Mann-Whitney $U$ test for non-parametric data. $p \leq 0.05$ was considered statistically significant.

\section{Results}

Amyloid deposition is greater in S20G islets In vitro culture for $144 \mathrm{~h}$ in 11.1 or $16.7 \mathrm{mmol} / 1$ glucose induced amyloid deposition in both $\mathrm{S} 20 \mathrm{G}$ and wild-type $\mathrm{h} I A P P$ islets (Fig. 1a-d). Following $144 \mathrm{~h}$ of culture in $11.1 \mathrm{mmol} / \mathrm{l} \mathrm{glu}-$ cose, amyloid prevalence was greater in S20G islets than in wild-type h $I A P P$ islets $(39.8 \pm 4.1 \%$ vs $14.5 \pm 2.9 \%$; Fig. $2 a)$. Similarly, amyloid severity was greater in $\mathrm{S} 20 \mathrm{G}$ islets than in wild-type $\mathrm{h} I A P P$ islets $(0.9 \pm 0.3$ vs $0.1 \pm 0.0 \%$; Fig. $2 \mathrm{~b})$. Culture in $16.7 \mathrm{mmol} / 1$ glucose resulted in increased amyloid deposition in both genotypes. In high glucose, $92 \%$ of the S20G islets contained amyloid deposits (Fig. 2a), with the degree of amyloid deposition being greater than that observed in wild-type $\mathrm{h} I A P P$ islets $(15.1 \pm 1.3 \%$ vs $11.5 \pm 1.3 \%$; Fig. 2b).

Beta cell apoptosis is increased and beta cell area decreased in S20G islets Increased amyloid deposition was associated with increased beta cell apoptosis (Figs 1e and 2c) and decreased beta cell area (Fig. 2d) in both wild-type and S20G hIAPP islets cultured in 16.7 vs $11.1 \mathrm{mmol} / 1$ glucose. Compared with wild-type hIAPP islets, S20G islets exhibited increased rates of beta cell apoptosis when cultured in $11.1(0.01 \pm 0.01 \%$ vs $0.00 \pm 0.00 \%$; Fig. $2 \mathrm{c})$ as well as in $16.7 \mathrm{mmol} / 1$ glucose $(0.61 \pm 0.07 \%$ vs $0.35 \pm 0.07 \%$; Fig. 2c). Compared with islets cultured in $11.1 \mathrm{mmol} / \mathrm{l} \mathrm{glu}-$ cose, beta cell area was decreased in $16.7 \mathrm{mmol} / 1$ glucose in both genotypes and beta cell area was decreased in S20G islets compared with wild-type $\mathrm{h} / A P P$ islets cultured in $16.7 \mathrm{mmol} / 1$ glucose (42.3 \pm 1.6 vs $46.9 \pm 2.4 \%$; Fig. 2 d).

Glucose-stimulated insulin secretion is reduced in S20G islets cultured in high glucose Islets were cultured in 11.1 or $16.7 \mathrm{mmol} / \mathrm{l}$ glucose for $144 \mathrm{~h}$, after which insulin and hIAPP mRNA, glucose-stimulated insulin (GSIS) and 

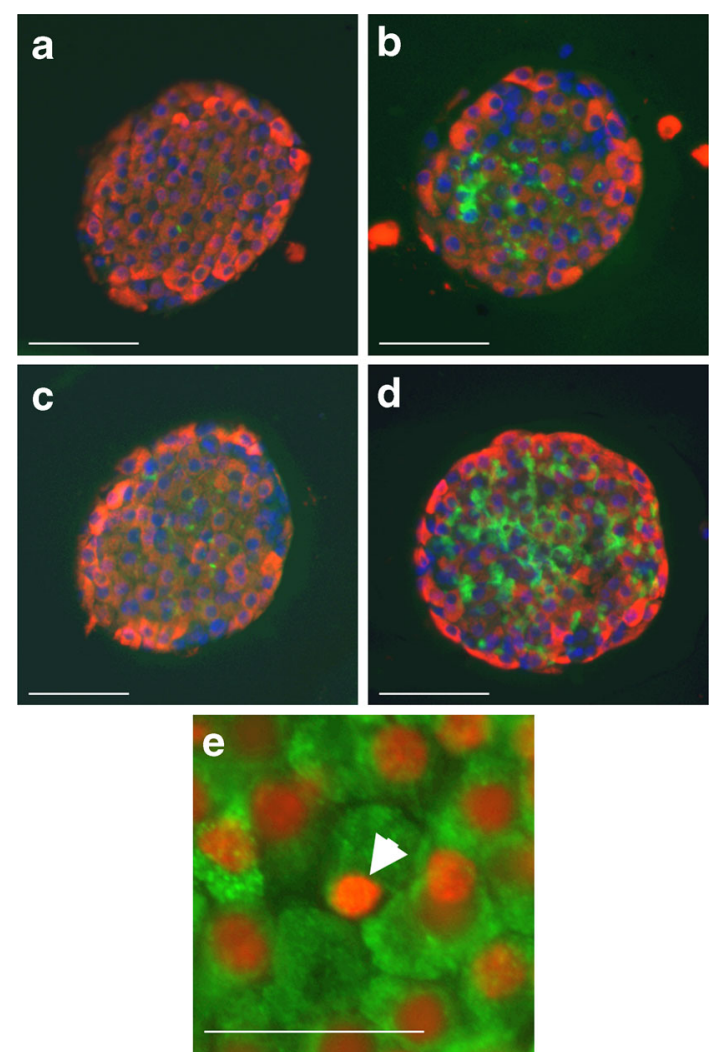

Fig. 1 Histological analysis of wild-type and S20G hIAPP islets after in vitro culture for $144 \mathrm{~h}$. (a-d) Representative images of single islets stained for insulin (red), amyloid (green) and nuclei (blue) of wild-type $\mathrm{h} I A P P$ islets cultured in $11.1 \mathrm{mmol} / \mathrm{l}$ glucose with amyloid severity $0.1 \%$ and insulin area/islet area $63.8 \%$ (a), wild-type $\mathrm{h} I A P P$ islets cultured in $16.7 \mathrm{mmol} / \mathrm{l}$ glucose with amyloid severity $8.5 \%$ and insulin area/islet area $52.8 \%$ (b), S20G hIAPP islets cultured in $11.1 \mathrm{mmol} / 1$ glucose with amyloid severity $1.0 \%$ and insulin area/islet area $60.3 \%$ (c) and S20G $\mathrm{h} I A P P$ islets cultured in $16.7 \mathrm{mmol} / 1$ glucose with amyloid severity $14.9 \%$ and insulin area/islet area $48.5 \%$ (d). (e) Islets were also stained with propidium iodide (red) and for insulin (green) and a representative image of a S20G islet cultured in $16.7 \mathrm{mmol} / \mathrm{l}$ glucose for $144 \mathrm{~h}$ indicating an apoptotic nucleus (arrow head) is shown. Scale bars, $50 \mu \mathrm{m}$. Magnification $\times 20$, except for $(\mathbf{e})$, where magnification is $\times 40$

hIAPP secretion, as well as insulin and hIAPP content, were measured (Figs 3 and 4).

Ins 2 mRNA levels were higher in $\mathrm{S} 20 \mathrm{G}$ islets than in wildtype $\mathrm{h} I A P P$ islets in both glucose concentrations (Fig. 3a). $\mathrm{h} I A P P$ mRNA levels did not differ between genotypes, but were increased in islets cultured in 16.7 compared with $11.1 \mathrm{mmol} / 1$ glucose (Fig. $4 \mathrm{a}$ ).

For both genotypes, insulin and hIAPP content was reduced in islets cultured in 16.7 compared with $11.1 \mathrm{mmol} / 1$ glucose (Figs $3 \mathrm{~b}$ and $4 \mathrm{~b}$ ). In $16.7 \mathrm{mmol} / \mathrm{l}$ glucose, insulin content was lower in $\mathrm{S} 20 \mathrm{G}$ than wild-type $\mathrm{h} I A P P$ islets $\left(22.4 \pm 2.1\right.$ vs $\left.37.4 \pm 4.4 \mathrm{nmol} \mathrm{l}^{-1}[5 \text { islets }]^{-1}\right)$, while hIAPP content did not differ between genotypes ( $1.22 \pm 0.07$ vs 1.33 $\pm 0.11 \mathrm{nmol} \mathrm{l}^{-1}[5 \text { islets }]^{-1}$ ).

In islets pre-cultured in $11.1 \mathrm{mmol} / \mathrm{l}$ glucose, basal insulin secretion and GSIS were similar between genotypes (Fig. 3c).
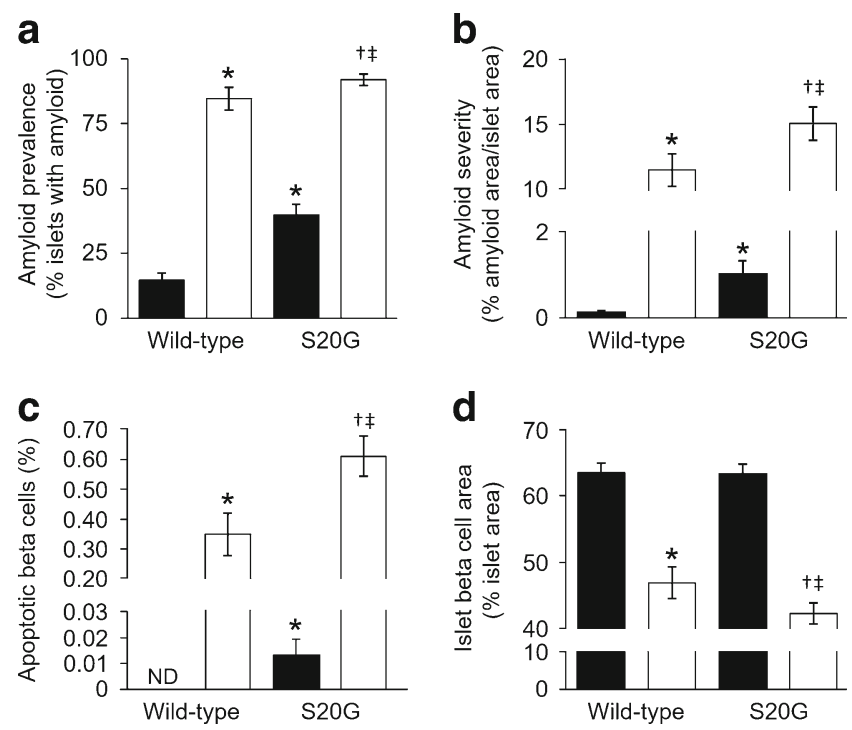

Fig. 2 Morphological assessment of isolated wild-type and S20G hIAPP islets. Islets were cultured for $144 \mathrm{~h}$ in media containing either $11.1(n=10-12)$ or $16.7 \mathrm{mmol} / \mathrm{l}(n=10-16)$ glucose. (a) Amyloid prevalence (proportion of islets with amyloid). (b) Amyloid severity (proportion of islet area occupied by amyloid). (c) Rate of beta cell apoptosis. (d) Fractional islet beta cell area. Black bars, $11.1 \mathrm{mmol} / 1$ glucose; white bars, $16.7 \mathrm{mmol} / 1$ glucose. ${ }^{*} p \leq 0.05$ vs wild-type islets cultured in $11.1 \mathrm{mmol} / 1$ glucose; ${ }^{\dagger} p \leq 0.05$ vs S20G islets cultured in $11.1 \mathrm{mmol} / 1$ glucose; ${ }^{\star} p \leq 0.05$ vs wild-type islets cultured in $16.7 \mathrm{mmol} / 1$ glucose; ND, not detected

In contrast, in islets pre-cultured in $16.7 \mathrm{mmol} / \mathrm{l}$ glucose, basal insulin secretion was similar between genotypes $(51.8 \pm 12.0 \mathrm{vs}$ $67.5 \pm 10.2$ pmol $\left.^{-1}[5 \text { islets }]^{-1} \mathrm{~h}^{-1}\right)$, but GSIS was decreased by $35 \%$ in S20G islets compared with wild-type $\mathrm{h} I A P P$ islets $\left(1895 \pm 208\right.$ vs $2905 \pm 244$ pmol l$\left.^{-1}[5 \text { islets }]^{-1} \mathrm{~h}^{-1}\right)$ (Fig. 3d). Glucose-stimulated hIAPP secretion was greater in wild-type $\mathrm{h} I A P P$ islets pre-cultured in 16.7 compared with $11.1 \mathrm{mmol} / 1$ glucose $\left(25.2 \pm 1.5\right.$ vs $5.1 \pm 0.4$ pmol l$\left.^{-1}[5 \text { islets }]^{-1} \mathrm{~h}^{-1}\right)$ (Fig. 4c). This increase was also observed in S20G islets $\left(27.2 \pm 4.0\right.$ vs $\left.6.7 \pm 0.6 \mathrm{pmol} \mathrm{l}^{-1}[5 \text { islets }]^{-1} \mathrm{~h}^{-1}\right)$. In contrast to GSIS, hIAPP release did not differ between genotypes following pre-culture in either glucose concentration (Fig. 4c).

When insulin release was normalised to content, fractional insulin release was greater in islets cultured for $144 \mathrm{~h}$ in $16.7 \mathrm{mmol} / \mathrm{l}$ glucose, but did not differ between genotypes (Fig. 3e). Similarly, fractional release of hIAPP was also greater following culture in $16.7 \mathrm{mmol} / \mathrm{l}$ glucose in both genotypes, and also did not differ between genotypes (Fig. 4d).

The ratio of glucose-stimulated hIAPP:insulin secretion was similar in both $\mathrm{h} I A P P$ genotypes pre-cultured in low glucose $(1.53 \pm 0.22$ vs $1.36 \pm 0.26 \%)$ and S20G $\mathrm{h} L A P P$ precultured in high glucose $(1.43 \pm 0.15 \%)$ (Fig. $4 \mathrm{e})$. When islets were pre-cultured in high glucose, the hIAPP:insulin ratio was lower in wild-type $\mathrm{h} I A P P$ islets than in S20G islets $(0.89$ $\pm 0.07 \%)$ and tended to be lower than for wild-type $\mathrm{h} I A P P$ islets pre-cultured in low glucose $(p=0.1)$. 


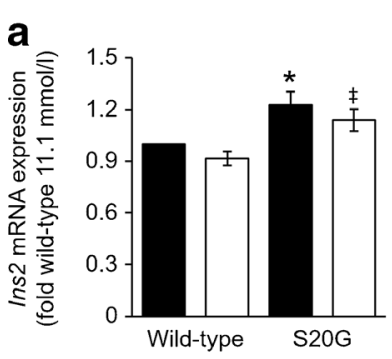

b
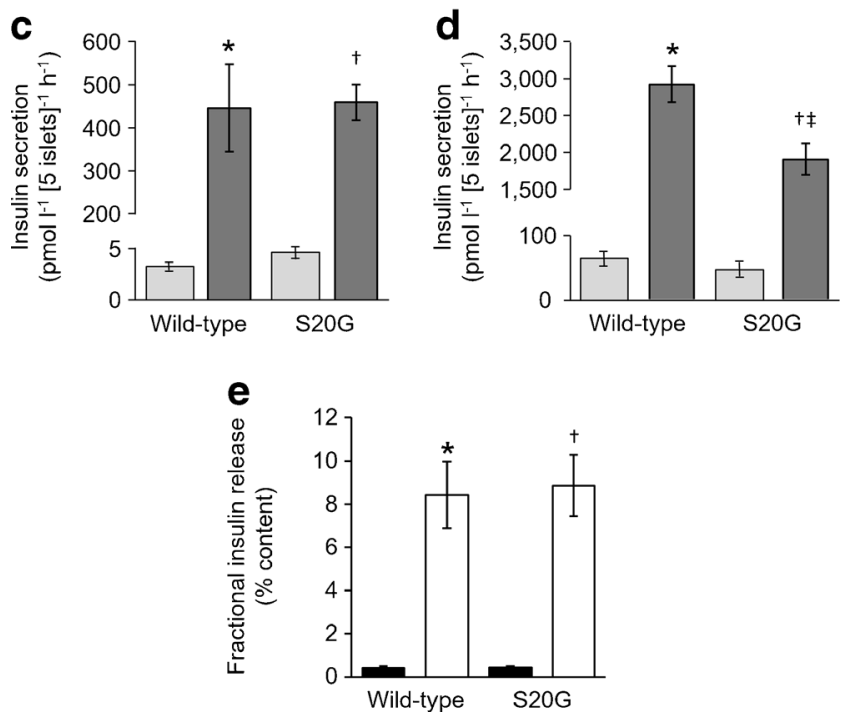

Fig. 3 Insulin assessments of isolated wild-type and $\mathrm{S} 20 \mathrm{G} \mathrm{h} L A P P$ islets. (a, b) Insulin mRNA (a) and insulin content (b) of islets measured after $144 \mathrm{~h}$ culture in media containing either 11.1 or $16.7 \mathrm{mmol} / 1$ glucose followed by $2.5 \mathrm{~h}$ in $2.8 \mathrm{mmol} / \mathrm{l}$ glucose. Black bars, $11.1 \mathrm{mmol} / \mathrm{l}$ glucose; white bars, $16.7 \mathrm{mmol} / \mathrm{l}$ glucose. (c, d) GSIS in response to $1 \mathrm{~h}$ of 2.8 or $20.0 \mathrm{mmol} / \mathrm{l}$ glucose following $144 \mathrm{~h}$ culture in media containing either $11.1 \mathrm{mmol} / 1$ glucose $(\mathbf{c})$ or $16.7 \mathrm{mmol} / 1$ glucose $(\mathbf{d})$. Light grey bars, $2.8 \mathrm{mmol} / 1$ glucose; dark grey bars, $20.0 \mathrm{mmol} / 1$ glucose. (e) GSIS normalised to insulin content. Black bars, $11.1 \mathrm{mmol} / 1$; white bars, $16.7 \mathrm{mmol} / \mathrm{l} . n=5$ experiments, except mRNA $n=7$. ${ }^{*} p \leq 0.05$ vs wildtype islets cultured in $11.1 \mathrm{mmol} / 1$ glucose; ${ }^{\dagger} p \leq 0.05 \mathrm{vs} \mathrm{S20G}$ islets cultured in $11.1 \mathrm{mmol} / 1$ glucose; ${ }^{\star} p \leq 0.05$ vs wild-type islets cultured in $16.7 \mathrm{mmol} / 1$ glucose. Secretion experiments: ${ }^{*} p \leq 0.05$ vs wild-type islets exposed to $2.8 \mathrm{mmol} / 1$ glucose; ${ }^{\dagger} p \leq 0.05$ vs S20G islets exposed to $2.8 \mathrm{mmol} / 1$ glucose; ${ }^{\ddagger} p \leq 0.05$ vs wild-type islets exposed to $20.0 \mathrm{mmol} / 1$ glucose

\section{Discussion}

We have demonstrated for the first time in primary islets with endogenous expression of the $\mathrm{S} 20 \mathrm{G}$ gene mutation of $\mathrm{h} I A P P$ that this substitution results in greater amounts of islet amyloid deposition than wild-type hIAPP. Further, under the amyloidpromoting condition of $16.7 \mathrm{mmol} / 1$ glucose, this increase in amyloid deposition is associated with an increase in beta cell apoptosis, a decrease in beta cell area and reduced GSIS, suggesting that the S20G substitution augments amyloid-induced islet damage.

Species differences exist in the IAPP amino acid sequence and with that the aggregation potential of the
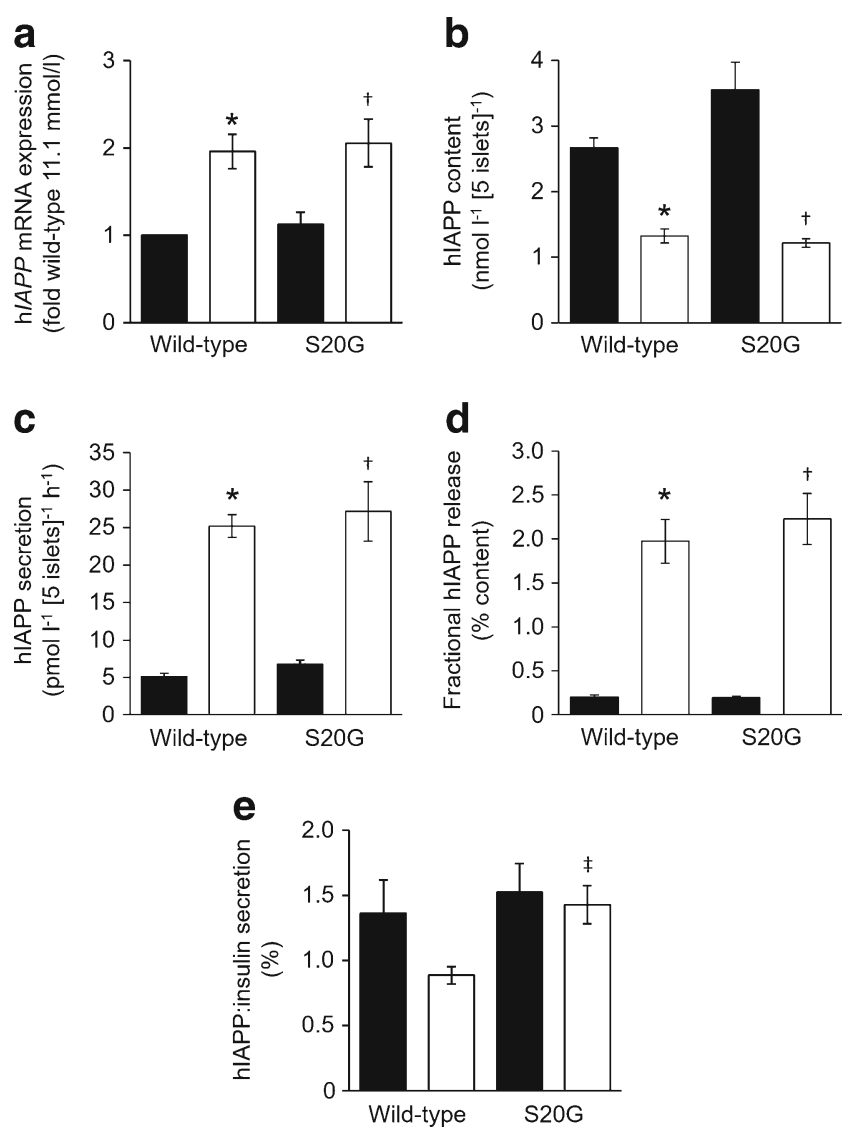

Fig. 4 hIAPP assessments of isolated wild-type and S20G hIAPP islets. (a, b) hIAPP mRNA (a) and hIAPP content (b) after $144 \mathrm{~h}$ culture in media containing either 11.1 or $16.7 \mathrm{mmol} / \mathrm{l}$ glucose. (c) Glucose-stimulated hIAPP secretion in response to $1 \mathrm{~h}$ of $20 \mathrm{mmol} / \mathrm{l}$ glucose following $144 \mathrm{~h}$ culture in media containing either 11.1 or $16.7 \mathrm{mmol} / \mathrm{l}$ glucose. (d) Glucose-stimulated hIAPP secretion normalised to hIAPP content. (e) Ratio of hIAPP:insulin released in response to $1 \mathrm{~h}$ of $20 \mathrm{mmol} / \mathrm{l}$ glucose following $144 \mathrm{~h}$ culture in media containing either 11.1 or $16.7 \mathrm{mmol} / 1$ glucose. Black bars, $11.1 \mathrm{mmol} / 1$ glucose; white bars, $16.7 \mathrm{mmol} / \mathrm{l}$ glucose. $n=5$ experiments, except mRNA $n=7 . * p \leq 0.05$ vs wild-type cultured in $11.1 \mathrm{mmol} / 1$ glucose; ${ }^{\dagger} p \leq 0.05$ vs S20G islets cultured in $11.1 \mathrm{mmol} / 1$ glucose; ${ }^{\ddagger} p \leq 0.05$ vs wild-type islets cultured in $16.7 \mathrm{mmol} / 1$ glucose

peptide. Early studies that compared the IAPP sequence of aggregation-prone and non-amyloidogenic IAPP concluded that amino acids 20-29 are critical for hIAPP aggregation and that substitutions within this sequence are responsible for the lack of aggregation in certain species [13]. The S20G substitution is located within this critical segment and a recent study explored the sensitivity of hIAPP aggregation to alterations at residue 20 in detail [4]. Consistent with earlier reports [5, 6], it found that the S20G substitution accelerated amyloid formation in a cell-free system using synthetic peptides. In addition, substitution of residue 20 to the bigger and positively charged amino acid lysine greatly slowed amyloid formation, further identifying residue 20 as a key determinant of aggregation behaviour [4]. 
The fibrillar structure of aggregated synthetic S20G hIAPP appears to be similar to that of wild-type hIAPP fibrils, with both variants being rich in beta sheet structures [4]. This suggests that islets expressing S20G or wild-type $\mathrm{h} I A P P$ should both form amyloid deposits. Indeed, we found that endogenous S20G hIAPP aggregates to form thioflavin S-detectable amyloid deposits in isolated islets. Further, these deposits were morphologically indistinguishable from those formed in islets expressing wild-type $\mathrm{h} I A P P$.

The greater amounts of islet amyloid we observed in S20G islets could be explained by either the S20G substitution rendering hIAPP more amyloidogenic [4-6] or an increase in hIAPP production and release. However, hIAPP production does not appear to be increased in S20G islets as the level of $\mathrm{h} I A P P$ mRNA did not differ between genotypes. Further, hIAPP content and secretion were also similar in the two genotypes. Thus, we favour the explanation that the increase in amyloid formation results from S20G being more amyloidogenic.

The observed increased rate of beta cell apoptosis in S20G islets was associated with a reduction in beta cell area and reduced insulin content. These changes could be expected to affect islet function. Indeed, GSIS was diminished, confirming that S20G islets exposed to a hyperglycaemic milieu are functionally impaired. Normalising the GSIS to insulin content showed that the amount of insulin released was proportional to islet insulin content in both genotypes. This observation suggests that the surviving beta cells in S20G islets cultured in $16.7 \mathrm{mmol} / \mathrm{l}$ glucose do release insulin, but do not appear to compensate for the reduced insulin secretion occurring as a result of greater beta cell loss by releasing an increased fraction of their content.

We also found that greater amounts of amyloid were formed in $\mathrm{S} 20 \mathrm{G}$ islets when cultured in $11.1 \mathrm{mmol} / 1$ glucose, despite hIAPP release by S20G islets being similar to that seen in wild-type islets. As we have found that amyloid formation is dependent on hIAPP secretion [14] and that this is the physiological glucose concentration for mouse islets, this observation again suggests that the threshold for amyloid formation may be lower in S20G islets than wild-type hIAPP islets. This increase in amyloid deposition in S20G islets was also associated with a marginal albeit significantly increased rate of beta cell apoptosis. However, this low rate of apoptosis did not lead to a detectable difference in beta cell area. These observations support the concept that individuals who are at high risk of developing type 2 diabetes and also carry the S20G gene mutation may be predisposed to develop islet amyloidosis at much lower glucose concentrations. Should this be the case, one could hypothesise that individuals with impaired glucose tolerance may be losing beta cells by this process, which ultimately results in greater beta cell loss and an earlier onset of diabetes than seen with wild-type hIAPP.
We used islets from mice in which the mouse Iapp gene was replaced with wild-type or $\mathrm{S} 20 \mathrm{G} \mathrm{h} I A P P$. It has previously been reported that these mice do not develop thioflavin S-detectable amyloid deposits following 18 months of highfat diet feeding [8], an observation that differs from what we documented with mice in which $\mathrm{h} I A P P$ was transgenically expressed under the control of the rat insulin promoter [15]. We believe this difference in in vivo amyloid deposition is most likely due to strain differences (C57BL/6 vs F1 $\mathrm{C} 57 \mathrm{BL} / 6 \times \mathrm{DBA} / 2$ ), as we have previously shown that the $\mathrm{DBA} / 2$ background is a critical determinant of amyloid formation in vivo [16]. Other factors could possibly have contributed: (1) differences in the endogenous mouse Iapp and transgenic rat insulin promoters that drive $\mathrm{h} I A P P$ expression; (2) the stimulus in vitro was glucose while in vivo it was high fat and (3) the in vitro model used isolated islets that are by definition not in situ within the pancreas and thus lack innervation and vascular flow.

It is of interest that we observed differences in insulin and $\mathrm{h} I A P P$ mRNA expression in response to increased glucose, with $\mathrm{h} I A P P$ expression increasing and insulin mRNA expression remaining unchanged. This observation is consistent with findings made using human islets [17]. Furthermore, in response to pre-culture in high glucose, in wild-type $\mathrm{h} I A P P$ islets we noticed a decrease in the ratio of hIAPP:insulin released. This was not the case for S20G islets. These observations suggest that there may be some differential regulation of the production of these two beta cell secretory products in response to glucose.

In conclusion, we found that $\mathrm{S} 20 \mathrm{G}$ islets are more prone to develop amyloid deposits, which in turn leads to loss of beta cells and decreased GSIS. These observations provide a potential explanation to why individuals carrying this gene mutation have an earlier onset of type 2 diabetes.

Acknowledgements We thank B. Barrow, M. Peters, J. Willard, P. Bergquist, D. Hackney, A. Rahman, J. Wilkins-Gutierrez and C. Ho (all Seattle Institute for Biomedical and Clinical Research, Seattle, WA, USA) for excellent technical support. We thank N. Eberhardt (Mayo Clinic and Foundation, Rochester, MN, USA) for providing the transgenic mice.

Funding This work was supported by the Department of Veterans Affairs grant BX001060 and NIH grants DK-017047, DK-007247, DK080945, DK-088082, DK-098506, DK-107022 and HL-007028. DTM was supported by a Swiss National Foundation Fellowship and the Dick and Julia McAbee Endowed Fellowship in Diabetes from the University of Washington. ATT was supported by an American Diabetes Association Mentor-Based Fellowship.

Duality of interest The authors declare that there is no duality of interest associated with this manuscript.

Contribution statement DTM designed the studies, performed research, analysed and interpreted the data and wrote the manuscript. LE performed research, analysed the data and reviewed/edited the manuscript. ATT, MFH, MM, SZ and RLH analysed and interpreted the data and reviewed/edited the manuscript. SEK contributed to the study design, 
analysed and interpreted the data and reviewed/edited the manuscript. All authors approved the final version. DTM is responsible for the integrity of the work as a whole.

\section{References}

1. Jurgens CA, Toukatly MN, Fligner CL et al (2011) Beta-cell loss and beta-cell apoptosis in human type 2 diabetes are related to islet amyloid deposition. Am J Pathol 178:2632-2640

2. Sakagashira S, Sanke T, Hanabusa T et al (1996) Missense mutation of amylin gene (S20G) in Japanese NIDDM patients. Diabetes 45: 1279-1281

3. Seino S, Study Group of Comprehensive Analysis of Genetic Factors in Diabetes Mellitus (2001) S20G mutation of the amylin gene is associated with Type II diabetes in Japanese. Diabetologia 44:906-909

4. Cao P, Tu LH, Abedini A et al (2012) Sensitivity of amyloid formation by human islet amyloid polypeptide to mutations at residue 20. J Mol Biol 421:282-295

5. Sakagashira S, Hiddinga HJ, Tateishi K et al (2000) S20G mutant amylin exhibits increased in vitro amyloidogenicity and increased intracellular cytotoxicity compared to wild-type amylin. Am J Pathol 157:2101-2109

6. Ma Z, Westermark GT, Sakagashira S et al (2001) Enhanced in vitro production of amyloid-like fibrils from mutant (S20G) islet amyloid polypeptide. Amyloid 8:242-249

7. Xu W, Jiang P, Mu Y (2009) Conformation preorganization: effects of S20G mutation on the structure of human islet amyloid polypeptide segment. J Phys Chem B 113:7308-7314

8. Hiddinga HJ, Sakagashira S, Ishigame M et al (2012) Expression of wild-type and mutant S20G hIAPP in physiologic knock-in mouse models fails to induce islet amyloid formation, but induces mild glucose intolerance. J Diabetes Investig 3:138-147

9. Scaglia L, Cahill CJ, Finegood DT, Bonner-Weir S (1997) Apoptosis participates in the remodeling of the endocrine pancreas in the neonatal rat. Endocrinology 138:1736-1741

10. Zraika S, Hull RL, Udayasankar J et al (2009) Oxidative stress is induced by islet amyloid formation and time-dependently mediates amyloid-induced beta cell apoptosis. Diabetologia 52:626-635

11. Meier DT, Entrup L, Templin AT et al (2015) Determination of optimal sample size for quantification of beta-cell area, amyloid area and beta-cell apoptosis in isolated islets. J Histochem Cytochem 63:663-673

12. Percy AJ, Trainor DA, Rittenhouse J, Phelps J, Koda JE (1996) Development of sensitive immunoassays to detect amylin and amylin-like peptides in unextracted plasma. Clin Chem 42:576-585

13. Westermark P, Engstrom U, Johnson KH, Westermark GT, Betsholtz C (1990) Islet amyloid polypeptide: pinpointing amino acid residues linked to amyloid fibril formation. Proc Natl Acad Sci U S A 87:5036-5040

14. Aston-Mourney K, Hull RL, Zraika S, Udayasankar J, Subramanian SL, Kahn SE (2011) Exendin-4 increases islet amyloid deposition but offsets the resultant beta cell toxicity in human islet amyloid polypeptide transgenic mouse islets. Diabetologia 54: 1756-1765

15. Hull RL, Andrikopoulos S, Verchere CB et al (2003) Increased dietary fat promotes islet amyloid formation and beta-cell secretory dysfunction in a transgenic mouse model of islet amyloid. Diabetes $52: 372-379$

16. Hull RL, Watts MR, Kodama K et al (2005) Genetic background determines the extent of islet amyloid formation in human islet amyloid polypeptide transgenic mice. Am J Physiol Endocrinol Metab 289:E703-E709

17. Gasa R, Gomis R, Casamitjana R, Novials A (2001) High glucose concentration favors the selective secretion of islet amyloid polypeptide through a constitutive secretory pathway in human pancreatic islets. Pancreas 22:307-310 